\title{
User satisfaction: Measurement and interpretation
}

\author{
Janet Harris, MA, Director of Health Care and Health Sciences, University of Oxford, Oxford, UK \\ Martin Westerby, MSc, Schools and Young People's Officer, Kensington, Chelsea and Westminster Health Authority, London, \\ $U K$
}

Tony Hill, MPH, FFPHM, Director of Public Health, South Humber Health Authority, UK

Tilly Sellers, BA, International HIV/AIFDS Technical Advisor, Khmer HIV/AIDS NGO Alliance, Cambodia

Allen Hutchinson, FFPHM, FRCGP, Professor of Public Health Medicine, University of Sheffield, Sheffield, UK

Correspondence: Janet Harris, Centre for Professional Development, University of Oxford, Littlegate House, 16/17 St Ebbes, Oxford OX1 1PT, UK

A paper presented at the inaugural meeting of the Clinical Effectiveness Unit, Faculty of Family Planning and Reproductive Health Care of the Royal College of Obstetricians and Gynaecologists, September 1999.

'A good evaluation releases the voice of the participants. It helps them to be heard, which for many people is a rare opportunity. It is through listening to this voice that the project workers and providers can understand the real needs and learn what activities and support would be most relevant and appropriate.'

\section{Summary}

Over the past 5 years there has been an increased interest in assessing users' satisfaction with health care services in England. Measuring and interpreting user satisfaction with reproductive and sexual health services can be complex, and efforts have met with varying degrees of success. This paper will summarise the methods that have been used to assess user satisfaction over the past 10 years, describe a different type of approach that has been recently used in England, and provide some suggestions for approaches that may be effective in improving clinical effectiveness in the new millennium.

\section{Key message points}

- Health professionals and researchers often develop evaluation methods with little input from service users.

- Lack of involvement can lead to 'solutions' that are not particularly appropriate for users.

- Providers' attitudes toward involving users in assessment need to be explored.

- Users should be involved in both evaluating services and making the improvements whenever possible.

- Credit for the improvements should be given to those who participated, to ensure ongoing participation in future evaluation.

\section{Key words}

consumer satisfaction, health care evaluation mechnisms, patient acceptance of health care

\section{Background}

Over the past 10 years, several initiatives have led to increased interest in assessing user satisfaction with sexual and reproductive health services. There has been a growing realisation that the process of service delivery can affect health outcomes. On an international and national level, health professionals have also acknowledged that users' attitudes toward services are an essential element of contraceptive uptake and continued use. ${ }^{2}$

Prior to the $1980 \mathrm{~s}$, evaluations of health care services focused on measuring quantifiable outcomes of care. For family planning services, this meant measuring the effectiveness of services by assessing outcomes such as trends in contraceptive prevalence or fertility rates. ${ }^{3}$ This emphasis on measuring outcomes was demonstrated in England's Health of the Nation strategy, which called for a $50 \%$ reduction in rates of pregnancy in the under $16 \mathrm{~s}$ by the year 2000. ${ }^{4}$ When evaluation is limited to outcomes measurement, services can become a 'black box ... for which inputs and outputs can be readily observed, but the connecting processes are not readily visible'. 5 In the field of sexual health, providers and researchers are now reacting to the government focus on outcomes by citing a number of other health care professionals who are demonstrating the importance of assessing the process of how services are delivered, as well as long-term outcomes. ${ }^{5-7}$

In sexual health services, it is essential to understand the connecting processes that encourage people to consider contraceptive use. Research shows that the way in which the service is delivered has a considerable impact upon contraceptive uptake, contraceptive continuation, and pregnancy rates. ${ }^{8}$ If the connecting process is not understood, then we are unable to say that a contraceptive service was truly responsible for the positive outcome, or conversely, that the service influenced discontinuation?

By 1997 there was increasing recognition that most district health authorities were experiencing problems in terms of achieving the outcomes set by the government. ${ }^{10}$ Failure to meet national targets led to a closer examination of the relationship between sexual health behaviour, the process of care and reduced pregnancy rates. Research indicated that there were a number of factors which could affect pregnancy rates, including awareness and accessibility of services as well as the quality of clinical care. ${ }^{11}$

Consumer involvement is an essential element to understanding the process of care and its relationship to pregnancy rates. On the international scene, there has been interest in exploring the quality of services from the users' perspective since the $1980 \mathrm{~s} .{ }^{12}$ Interest in the UK, however, was not sparked until the 1990s, when National Health Service reforms emphasised the importance of being accountable to patients. In the field of sexual health, it has been suggested that 'health care purchasers and those who provide contraceptive services in many different settings must extend their assessment of provision of services to encompass the experience of service users'. ${ }^{13}$

\section{Methods for assessing user satisfaction}

Obtaining users' views is a relatively new initiative in UK health care, and methods for working with users to assess 
sexual health services are still being developed. The first wave of assessments in sexual health that was conducted in the UK was designed by service providers, funders and researchers. In most cases, experts identified the issues that needed to be explored, and used questionnaires or structured interviews to obtain data on the quality of care.

Initially satisfaction assessments tended to focus on measurable aspects of quality, such as the accessibility of services. Contraceptive service assessments focused on user satisfaction with the clinic locations, the opening hours, the appointment systems, and the waiting times.

There are several potential problems with this sort of approach to assessing user satisfaction (Figure 1). When experts design the questions, there is a risk that the issues that are most important to users will not be represented. It is true that the locations of clinics and opening hours can be influential in service use, but there are a number of other factors that may be of equal importance. ${ }^{14}$ These include 'cognitive accessibility' and 'psychosocial accessibility', which refer to potential users' awareness of local services and the psychological, attitudinal and social constraints that may hinder access. ${ }^{3}$ When questionnaires and interviews are tightly structured, the ability of users to offer comments on their real concerns can be limited. Responses to questions may reflect a 'courtesy bias', where service users tend to tell the provider what they want to hear. This bias can carry over into the analysis and use of the findings. When reviewing the data that are obtained - from young people in particular there may be a tendency for professionals to believe that 'they know best'. ${ }^{15,16}$ If service users' experiences are undervalued, then there is the subsequent risk that health providers will offer both information and services that are not meaningful to the user. ${ }^{17,18}$

Over the past few years there has been some interest in working with users in a different way to explore the linkages between access, quality, and timely and consistent use of services. Some organisations are beginning to use a more open-ended approach with more interaction between providers and users, such as the focus groups that are used by Brook Advisory Service. There appear to be, however, several remaining challenges to assessing user satisfaction. First, providers' attitudes toward user involvement need to be taken into consideration. The health service is often demand-driven rather than needs-led, and providers may have little experience consulting with users. Secondly, methods need to be developed which actively involve the user, in order to obtain good information on the ways in which services need to be modified. And finally, processes need to be established for considering the findings and how they may be used to improve care.

Figure 1 Assessing user satisfaction: A risky scenario

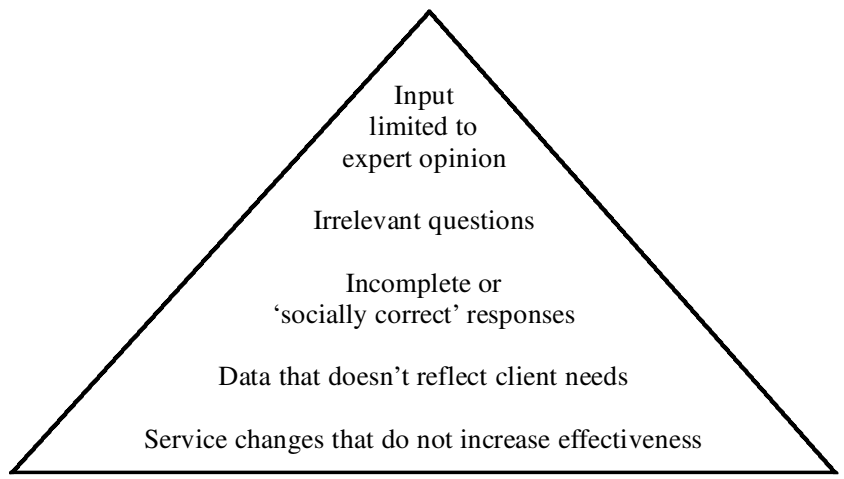

A different approach to assessing user satisfaction

More inclusive methods for assessing user satisfaction have been developed through several projects funded by NHS Research and Development, the Department of Health, NHS Executive Trent Region, and East Riding Health Authority. ${ }^{19-23}$ These projects are using participatory approaches that not only learn about users' views, but also actively involve users in the process of modifying contraceptive information and services.

Participatory approaches emphasise the involvement of potential beneficiaries in developing a plan for improving health care services. ${ }^{24}$ The process is initially co-ordinated by a facilitator, who introduces participatory tools and techniques to service providers who are interested in appraising services. The role of the facilitator is to suggest tools for exploring different issues as they arise, to check and verify information during group discussion, and to ensure that the information that is generated captures the diverse views of local people.

The research relationship is therefore a process whereby those who provide the information also take part in the change process. ${ }^{25}$ The experiences of potential users and actual users are taken up and applied immediately to modify the direction of the programme. This process occurs with varying degrees of participation. ${ }^{26,27}$ There are some indications from the project work that greater levels of participation may increase service use.

Table 1 Assessing user satisfaction: Levels of participation

\begin{tabular}{|c|c|c|}
\hline $\begin{array}{l}\text { Level of } \\
\text { Participation }\end{array}$ & Definition & Type of action \\
\hline $\begin{array}{l}\text { Co-option } \\
\text { users }\end{array}$ & Tokenism or manipulation & Action 'on' service \\
\hline $\begin{array}{l}\text { Co-operation } \\
\text { users }\end{array}$ & Tasks and incentives given & Action 'for' service \\
\hline Consultation & $\begin{array}{l}\text { External analysis of young } \\
\text { people's opinions }\end{array}$ & $\begin{array}{l}\text { Action 'for/with' service } \\
\text { users }\end{array}$ \\
\hline Collaboration & $\begin{array}{l}\text { Local and external } \\
\text { discussion }\end{array}$ & $\begin{array}{l}\text { Action 'with' service } \\
\text { users }\end{array}$ \\
\hline Co-learning & $\begin{array}{l}\text { Sharing of knowledge and } \\
\text { planning }\end{array}$ & $\begin{array}{l}\text { Action 'with/by' service } \\
\text { users }\end{array}$ \\
\hline Collective action & Locally determined agenda & $\begin{array}{l}\text { Action 'by' service } \\
\text { users }\end{array}$ \\
\hline
\end{tabular}

Participatory approaches use a variety of research tools to collect information, ranging from semi-structured interviewing and group work to the use of visual tools. The use of visual tools enables people who may be uncomfortable about their level of literacy to actively participate. The approach enables participation by a large number of people that may eventually need contraceptive services. Information may be shared not only on the structural aspects of services, but also on other, less tangible barriers that may inhibit information seeking or contraceptive use.

The two projects that have used a participatory approach to appraising sexual health services were based in East Yorkshire and Lincolnshire. In these projects, participatory appraisal was used to:

- explore providers' attitudes toward assessing satisfaction

- learn about awareness of local services and sexual health resources

- explore the pattern of daily lives to identify potential conflicts with service locations and hours

- find out about administrative, economic, psychosocial and clinical barriers to service use

- generate possible solutions

- identify barriers to changing services 
- $\quad$ set priorities

- act on the recommendations.

The process of obtaining user views was set within a wider implementation framework that included plans for using the data generated by participants to improve the effectiveness of the service.

The East Yorkshire project involved 1000 young people, parents, teachers, youth workers and health care professionals in an appraisal of services that aimed to reduce teenage pregnancy. The Lincolnshire project worked with over 300 young people and sexual health service providers to compare young people's needs to the services on offer.

In each of the projects, providers were first contacted in order to explain the approach and to generate interest in participating. Providers who wanted to appraise their services were offered participatory appraisal training, which demonstrated the philosophy of involving potential service users as well as the use of visual tools. During the second stage of the projects, providers and participants addressed the types of issues shown in Table $2 .^{28}$

\section{Lessons from the projects}

The approach proved to be more useful than interviews and questionnaires that had been previously used in the same geographical areas, because it allowed participants to choose what was important while giving providers insight into problems with service use. In many cases, providers had already made changes, or were considering changes to services, which did not necessarily reflect users' needs. The participatory information was used to evaluate these changes and modify them where necessary. For example, young people drew maps of where they knew services were located, which demonstrated that people viewed 'informal' sources of information and contraception, such as friends, pubs and clubs, to be just as important as school-based and clinical resources. This information had important implications in terms of effectively publicising sexual health services through more informal channels. Brainstorming produced lists that contained some misconceptions of what was on offer. This information proved useful in terms of modifying publicity to correct misconceptions. Timelines depicting young persons' sexual health experiences showed that they had different needs as potential users, or new users, than they had when they were more experienced in service use.

Young people listed many different types of barriers to accessing sexual health information and services. These included feelings about accessing services, concerns about privacy and confidentiality, lack of experience, lack of specific skills or knowledge, and structural aspects of the service such as appointment systems and location. Participants said that services should be easy to find, confidential, open at convenient times, welcoming, informative, have skilled staff, and offer a range of contraceptive services and testing.

These findings are very similar to those found in other assessments of user satisfaction that have been conducted in England. ${ }^{29}$ The experience of this set of participatory projects, however, demonstrated that providers do not always understand the information that is provided by users in surveys and questionnaires. As a result, changes in service may not actually represent an improvement from the user's point of view. For example, when users state that they need services that are easy to find, providers have traditionally responded by advertising services more widely. The clinic hours and locations have been made available via the Yellow Pages, the Web, and through local helplines, to name a few 'solutions'. Despite service providers' responses, participatory appraisal tools showed that there are still a number of problems associated with finding a clinic. Some young people cannot find information in the Yellow Pages because they don't know which terms to use when looking up the location of the family planning clinics. Many do not have access to the Web or know how to use it. Others manage to find the number for a clinic or a helpline, but do not have access to a private telephone where they can make a call for an appointment.

According to the participants, other methods of advertising should be considered. Participants pointed out that there is a huge amount of information that is informally exchanged, on topics such as where to get contraception, but this is rarely acknowledged by health professionals. A potentially powerful source of informal advertising is, therefore, left untapped. Young people across the participatory appraisal projects stated that advertising needs to be done in the places where young people find themselves - in school and college, in pubs and clubs, in youth centres, on buses and in shopping areas.

When users state that they need confidential services, providers have responded by putting up posters in clinics that say the service is confidential. Some clinics are in 'unexposed' locations, or in a multi-purpose building where the service user's specific needs will not be apparent. Health care staff have described and explained what

Table 2 Participatory appraisal of sexual health issues

\begin{tabular}{|c|c|c|}
\hline General questions & Areas to explore & Suggested tools \\
\hline 1. Awareness: What services do young people use? & $\begin{array}{l}\text { Which services are available? Where are services available? } \\
\text { What do these services offer? } \\
\text { Do young people use different services at different stages? }\end{array}$ & $\begin{array}{l}\text { Mapping } \\
\text { Brainstorm } \\
\text { Timeline }\end{array}$ \\
\hline 2. Daily lives: What do young people do each day? & What do young people do during each day? & Daily routine chart \\
\hline When do they have the opportunity to use services? & $\begin{array}{l}\text { Are there seasonal differences in activities and service use? } \\
\text { Do young people's activities change over time? }\end{array}$ & $\begin{array}{l}\text { Seasonal calendar } \\
\text { Timeline }\end{array}$ \\
\hline 3. Access to the service: What are available services like? & What are the barriers to accessing services? & Spider diagram \\
\hline $\begin{array}{l}\text { What are the administrative, economic, psychosocial and } \\
\text { clinical barriers? }\end{array}$ & $\begin{array}{l}\text { Which type of service has the least/most significant barriers? } \\
\text { Why don't young people use services? What are the effects of } \\
\text { them not using services? } \\
\text { How important is each service? How do they relate to each other? }\end{array}$ & $\begin{array}{l}\text { Criteria/matrix ranking } \\
\text { Causal impact diagram } \\
\text { Venn diagram }\end{array}$ \\
\hline $\begin{array}{l}\text { 4. Recommendations: What should services be like in the } \\
\text { future, and what should they offer? }\end{array}$ & $\begin{array}{l}\text { What does an ideal service look like? } \\
\text { What other factors make an ideal service? } \\
\text { Why are these factors important? } \\
\text { Given existing constraints, which recommendations will be most } \\
\text { feasible to implement while meeting users' needs? }\end{array}$ & $\begin{array}{l}\text { Mapping } \\
\text { Discussion }\end{array}$ \\
\hline 5. Priority setting: Which criteria are most important? & Is it possible to say which criteria are most important? Why? & $\begin{array}{l}\text { Pairwise ranking } \\
\text { Evaluation wheel }\end{array}$ \\
\hline
\end{tabular}


confidentiality means, and assured people that details will be taken privately. It is made clear that attendance is not shared with others. Again, these are all good measures to adopt, but will only go some way toward addressing an overwhelming concern that 'people will see me and tell my friends and family'. Some of this concern about confidentiality is related to the social stigma of needing contraceptive advice and services. Participants said that reassuring people about confidentiality after they have arrived in the clinic will not be enough. Service providers need to go out into schools and other community settings and 'normalise' the need for the service.

When users ask for convenient opening times, providers have responded by adding Saturday morning clinics as well as after-school times for young people. These may have increased access in some communities, but daily routine charts showed that young people are not up early enough on Saturdays to get to the clinics, and after-school clinics may conflict with other after-school activities. As convenient hours can mean different things to different people, the changes in opening hours should be monitored over time to assess whether the changes have increased utilisation.

When users say that services should be welcoming, providers have responded by training receptionists in the importance of a positive first response, getting rid of uniforms, improving sign posting, changing the name of the service, improving the waiting room environment, and seeing users with their friends or partners. All of these things can help to create a welcoming atmosphere, once people are actually in the clinic. The projects found, however, that if young people anticipated an unwelcome atmosphere, then they were much more reluctant to use a service. Participants stated that people need to anticipate a welcome, and one way to ensure that they will feel welcome is to conduct outreach sessions before they actually have to contact a clinic.

Many users ask for services that are informative, with staff who have expertise in contraceptive issues. Participants pointed out that providers' views on essential information do not always match the users' needs. Many young people, for example, do not want or need information that simply focuses on physiology and reproductive biology. They feel that this information would be far more useful and relevant if it was put in the context of discussing values and relationships. There is also an element of needing to build up a long-term association with a service, so that information can be obtained in small and understandable chunks on an asneeded basis. The freedom to ask questions, and to get all of your questions answered, is rated very highly.

\section{Discussion}

Users' views of services can be obtained through the use of surveys and questionnaires. It should be remembered, however, that these methods of collecting information will at best serve as an early warning system of potential mismatches between users' needs and what is actually on offer. The use of written information is also vulnerable to misinterpretation by providers, who may believe that they are responding to expressed needs when users actually are asking for something that is very different. In contraceptive service provision, the opinions of users about a service may influence their initial request for contraception, as well as their attitude toward returning when experiencing problems with a particular method. Participatory methods for assessing user views can serve two purposes: they not only provide information about the responsiveness of a service, but can also be used to establish and maintain a relationship with potential and actual users which will increase utilisation over time.

\section{Assessing user satisfaction: Next steps}

Based on the experiences in the projects, the following suggestions are made for assessing user satisfaction with contraceptive services:

Consider providers' attitudes toward assessment. Some providers were quite enthusiastic, while others were reluctant to participate for a variety of reasons. They were concerned that the findings would reflect badly on their service, or would be used to cut services. Some thought that the exercise would take too much time and put a strain on already limited resources. In some cases, providers stated that they were quite experienced and already knew what services should be provided (despite the fact that no consultation had occurred). In other cases, providers wanted to participate, but were unable to convince management of the need for the appraisal

Conduct assessments both 'outside' and 'inside' the door. There are a large number of factors that influence attitudes toward contraceptive use before potential service users actually reach the clinic door. While 'outside' the door, potential barriers include administrative accessibility, economic accessibility, cognitive accessibility, and psychosocial accessibility. When 'inside' the door, users are influenced by overall quality of care and clinical barriers, such as the quality of communication between clinicians and users, as well the contraceptive choices on offer. Ideally, users should have an opportunity to comment on all of these areas. Assessments can be conducted in outside settings via schools and youth clubs.

Ask participants to rate the feasibility of their suggestions. In some cases, participants made recommendations that at first glance appeared unrealistic, such as 'have a 24-hour service'. When the reasons behind these suggestions were explored, however, participants were able to clarify what type of access was needed for their daily schedules. Participants were also able to rate recommendations in terms of high impact and high feasibility, which was very useful information for providers. Many providers were impressed by the pragmatic and realistic recommendations that were offered by young people.

Explore providers' concerns about responding to users' needs. If some providers do not believe that the suggested changes are feasible or desirable, then it is unlikely that the changes will be supported by everyone. The process of acting on recommendations is a two-way street, where everyone needs to have input about the feasibility of change.

Respond to recommendations quickly. Once interest has been generated in assessing satisfaction, it is important to keep people updated on progress. This can be done via posters in the settings where participants met, as well as the settings where people stated that they access informal information.

Start small. As a first step, respond to the suggestions that can be implemented quickly, with the least resistance. This action will reinforce the view that users' recommendations are important.

Involve users whenever possible in implementing recommendations. A number of recommendations were implemented with no additional resources, including time. Participants were willing to volunteer time to modify leaflets, design publicity for a clinic, or advertise it via word of mouth. In other cases, participants worked with local 
groups or school and clinic staff, thereby reducing the amount of time that had to be devoted by service providers.

Explore the linkages between access, quality, and timely and consistent use of services. Very little research has been done on the potential impact of involving users, in terms of increased service utilisation. The experience of the projects showed, however, that when users were involved in designing publicity for new services, the services were used more frequently at start-up. Continued involvement may promote both initial access, and consistent service use over time.

Clearly credit the changes to users' input. Where ongoing evaluation shows that services have improved, it is important to give credit for the successful change to all who participated in making it happen.

\section{Acknowledgements}

We would like to thank NHS Executive Trent Region, East Riding Health Authority, and the NHS R\&D Programme (Mother and Child Health) for funding these projects, as well as acknowledging the many participants.

\section{Statement on funding and competing interests}

Funding. None.

Competing interests. None.

References

Laurie E. Ideas for the evaluation of community participation initiatives. Royal College of

ruce J. Fundamental elements in the quality of care: A simple framework. Studies in Family

The Magnani RJ, et al. Access, quality of care and medical barriers in family planning programs. International Family Planning Perspectives 1995; 21: 64-69 and 74.
Department of Health. The Health of the Nation: A Strategy for Health in England. London: HMSO 1992.

Everitt A. Values and evidence in evaluating community health projects. Critical Public Health

Davies HTO. Beyond health outcomes: the advantages of measuring process. Journal of Evaluation in Clinical Practice 1998; 4(1): 31-38.

Baker R. The surgery satisfaction questionnaire. Leicester: The Eli Lilly National Clinical Audit Centre, 1991.

Jain A. Fertility reduction and the quality of family planning services. Studies in Family Planning 1989; 20: 1-16.

Stahler GJ, DuCette JP. Evaluating adolescent pregnancy programs: rethinking our priorities Family Planning Perspectives 1991; 23(3): 129-133

10 Adler MW. Sexual health - a Health of the Nation failure. British Medical Journal 1997; 314 $1743-1747$

11 Bruce, J. Fundamental elements in the quality of care: A simple framework. Studies in Family Planning 1990; 21: 61-66.

12 Hermalin A, Entwhistle B. Future directions in the analysis of contraceptive availability Proceedings of the International Population Conference, Florence, 1985. International Unio for the Scientific Study of Population. Liege, 1985.

ices. Quality in Health Care 1997; 6: 59.

Tsui AO, Ochoa LJ. Service proximity as a determinant of contraceptive behaviour: Evidence rom cross-nations Planning P. Citizen WHO Regional Publications European Series 1991:37:477-496.

16 Levin LL. Public participation in health care quality. Journal of Epidemiology and Community Health 1995; 49: 348-353

Pritchard P. Community involvement in a changing world. Royal College of General Practitioners Occasional Paper 1994; 64: 26-28.

Brown I. The organisation of participation in general practice. Royal College of Genera Practitioners Occasional Paper 1994; 64: 1-4.

19 Harris J, Jones A. Auditing safer sex and contraception. Hull: University of Hull, 1998.

2 Jones A, Harris J. Evaluating Contraceptive Services for Teenagers. London: Royal College of

21 Harris J, Jones A. Ensuring the quality of contraceptive services. In Y. Carter, C. Moss \& A Weyman (eds) RCGP Handbook of Sexual Health in Primary Care. London: Royal College of Reners, 1998.

22 Harris JL, Hutchinson A, Sellers T. User-Oriented Strategies for Preventing Unintended Pregnancy in

23 Harris JL, Westerby M, Hill T Evaluating Commun Trent Final Report. Hull: University of Hull, 2000.

24 Chambers R. Whose Reality Counts? London: Intermediate Technology Publications, 1997. Hart E, Bond M. Action Research for Health and Social Care. Buckingham: Open University Press, 1995

26 Cornwall A, Jewkes R. What is participatory research? Social Science and Medicine 1995 1(12): $1667-1676$

27 Cornwall A. Toward participatory practice: participatory rural appraisal (PRA) in K. de Koning Wears 1996

Westerby M, Harris J, Sellers I, Hill T. How to do it: Suggested process for conducting participatory evaluation of community sexual health services. Hull: 